\title{
Investigating the water consumption for electricity generation at Turkish power plants
}

\author{
Balkess El-Khozondar, ${ }^{1, *}$, and Merih Aydınalp Koksal \\ ${ }^{1}$ Department of Environmental Engineering, Hacettepe University, 06800, Beytepe, Ankara, Turkey
}

\begin{abstract}
The water-energy intertwined relationship has recently gained more importance due to the high water consumption in the energy sector and to the limited availability of the water resources. The energy and electricity demand of Turkey is increasing rapidly in the last two decades. More thermal power plants are expected to be built in the near future to supply the rapidly increasing demand in Turkey which will put pressure on water availability. In this study, the water consumption for electricity generation at Turkish power plants is investigated. The main objectives of this study are to identify the amount of water consumed to generate $1 \mathrm{kWh}$ of electricity for each generation technology currently used in Turkey and to investigate ways to reduce the water consumption at power plants expected to be built in the near future to supply the increasing demand. The various electricity generation technology mixture scenarios are analyzed to determine the future total and per generation water consumption, and water savings based on changes of cooling systems used for each technology. The Long-range Energy Alternatives Planning (LEAP) program is used to determine the minimum water consuming electricity generation technology mixtures using optimization approaches between 2017 and 2035.
\end{abstract}

\section{Introduction}

Energy production is a water-intensive process in which water is used for fuel extraction, fuel processing, and electricity generation. Processes such as water treatment, desalination, water transportation, pumping require energy to provide water services. The energy and water related processes are closely interacted, thus this interaction is called water-energy nexus.

The global demand for electricity, and hence electricity generation, is continuously increasing and this results in an increase in the amount of water consumed in these processes. The amount of water consumption depends on the technology used for electricity generation. Majority of the global electricity is generated at thermoelectric power plants which use significant amount of water especially at the cooling systems. Once through, wet closed loop, and dry cooling are the most common cooling systems used at thermoelectric power plants [1]. The once through cooling system withdraws a large amount of water from a nearby water body, such as ocean, river, lake, pond or canal. After this water passes through the condenser, it is sent back to the water body where it is withdrawn. This type of cooling system has low capital and operating costs, and has low water consumption which is indirectly consumed at

\footnotetext{
*Corresponding author: balkess@hacettepe.edu.tr
} 
higher temperatures [1-3]. In the wet cooling towers, the water is pumped back to the cooling tower after condensing the steam. While this system does not withdraw large amounts of water, it consumes more water than the once through system during the evaporating process at the cooling tower $[1,4]$. Another method used at thermoelectric power plants is the dry cooling system in which air flows across the steam in tube arrays to condense it [5].

In some cases, the water deficiency can be a problem restricting the electricity generation at location where there is water scarcity. Hence, it is important to investigate the total amount of water used per generated electricity and also to specify the water consumption of the various processes during electricity generation at power plants. Since the most water consumption at the power plants occur at the cooling systems, it is important to focus on analyzing the water consumption at various types of cooling systems.

In the open literature, there are many studies on determining the amount of water consumption per electricity generation $(\mathrm{L} / \mathrm{MWh})$ at the power plant. Macknick et al. analyzed the water consumption at various US power plants in 2011. They took into account the water consumption in the operational phase only. The results of their study showed that thermal power plants with wet cooling tower systems consume more water per unit of generated electricity than the once through cooling systems. Furthermore, the coal and lignite power plants consume the highest amount of water among all types of plants. Whereas; photovoltaic (PV) and wind as renewable power plants, and concentrated solar power (CSP), Stirling Engine technology, and natural gas combined cycle power plants with dry cooling systems have the lowest water consumption factors (WCF) [6].

Delgado and her colleagues did not stop in just examining the water consumption data obtained from power plants, they also developed a simple model to determine the water consumption per generated electricity for a whole range of thermal power plants. The model is based on analyzing the water and heat flows in the power plants. In another study, Dale and his colleagues developed a model using two popular simulation tools (LEAP and WEAP) to define the impact of the climate change on the regional water and energy systems. In this study, data from some power plants at California is used to check the vulnerability of energy and water planning systems [7].

In US, many studies are conducted to compare the water consumption of alternative cooling systems of the electricity generation power plants. The systems are compared from several points, such as cost, the amount of water consumption, and environmental impacts. As a result, the amount of water consumption reduces nearly by $95 \%$ when wet cooling systems are replaced by dry cooling systems [8]. However, the dry cooling systems have lower efficiencies due to the heat capacity difference of water and air, and higher capital costs than those of the wet ones.

This study covers two main objectives; one is to identify the amount of water consumed $\left(\mathrm{m}^{3}\right)$ to generate $1 \mathrm{GWh}$ of electricity based on each generation technology currently used in Turkey, and the other one is to investigate ways to reduce the water consumption per electricity generation at power plants expected to be built in the near future to supply the increasing demand. This paper contains four sections. In the first section, general background information about the study is presented. The second section includes the methodology that is used in water consumption calculations and the application of scenarios to the model. In the third section, the results and discussions are provided. The conclusions are given in the fourth section of the paper.

\section{Methodology}

The methodology of this study consists of multiple steps which can be divided into three main stages; data gathering and analysis, model development, and scenario applications. The following sections describe these three stages in detail. 


\subsection{Data gathering and analysis}

The installed capacity, electricity production, cooling system type, fuel type, and technology data of all power plants operating in 2016 at Turkey (approximately 1581 power plants of which 361 are thermoelectric power plants) are gathered from various sources [9-13]. The water consumption data of Turkish power plants are not available for public access. Thus, $\mathrm{WCF}\left(\mathrm{m}^{3} / \mathrm{GWh}\right)$ for all power generation technologies currently operating in Turkey are gathered from several studies $[6,14,15]$. These factors are then used to calculate the water consumption of 361 thermoelectric power plants using the below equation.

$$
P P W C=\sum_{i}^{M} \sum_{j}^{N}\left(G E N_{i, j} \times W C F_{i, j}\right)
$$

where, PPWC is the water consumption of all thermoelectric power plants $\left(\mathrm{m}^{3}\right)$, GEN is the amount of electricity generated $(\mathrm{GWh})$ at each thermoelectric power plant, WCF is the water consumption factor based on generation technology and cooling system type $\left(\mathrm{m}^{3} / \mathrm{GWh}\right), \mathrm{j}$ is the power plant with specific cooling system in each generation technology, $\mathrm{j}$ is the power plant with specific generation technology, $M$ is the number of power plant with specific cooling system in each generation technology, and $\mathrm{N}$ is the number of power plant with specific generation technology.

\subsection{Model development}

The electricity generation model based on various generation technologies is developed using Long Range Energy Alternatives Planning (LEAP) until 2035 taking 2016 as the base year. LEAP supports various electricity generation technologies and facilitates the tracking of the energy generation based on the available resources and demand estimates. LEAP operates at two levels; where built-in equations are used for energy, emissions, cost-benefit, etc. calculations, or these equations can be entered as spreadsheet-like expressions by the user [16].

In the demand analysis part, the annual electricity demand estimates between 2017 and 2035 obtained from [17] are entered to examine how the total electricity generation based on various technologies will be dispatched over the study period by applying various scenarios. In this study, the demand is specified as a single branch from the electricity generation over the analysis time.

Electricity generation, distributing, and dispatching losses are placed in the transformation analysis section in LEAP. Power plant lifetime, efficiency, maximum availability, and operation and investment costs are the technical parameters in LEAP. The analysis process starts with calculating the electricity requirements for each year according to the dispatch rule, followed by the cost calculations. These steps are repeated for each year, for each module such as natural gas, coal, solar, etc. In this study, the transformation section just includes one branch which is electricity generation. The electricity generation includes the resources modules which are used to supply the electricity demand. As the distribution losses are not included in this study, the dispatch rule is used as the full capacity and the technical factors are entered for each module. The optimization model is based on water consumption for this study, however there is no factor that takes into account the water consumption in LEAP. Thus, the variable operation and maintenance cost parameter of the model is replaced by the WCF and the other costs are assumed to have a value of one unit for all modules. In addition to this, the renewable resources are limited in the maximum capacity section in LEAP using the potential of Turkey for each type [17]. The "Interpolation (Interp.)" function of LEAP is used in this study to calculate the straight-line change between specified pairs of data years and values [16]. After developing the model at LEAP, the 
generation technology mixtures between 2017 and 2035 are optimized based on the scenarios given in Table 1.

Table 1. Description of the scenarios applied to the model.

\begin{tabular}{|c|l|}
\hline Scenario Name & \multicolumn{1}{c|}{ Scenario Description } \\
\hline $\begin{array}{c}\text { Business as usual } \\
\text { (BAU) }\end{array}$ & $\begin{array}{l}\text { The distribution of each generation technology will not change over } \\
\text { the period of the study and average WCF of the cooling technologies } \\
\text { will be used for each generation technology. }\end{array}$ \\
\hline $\begin{array}{c}\text { Optimization } \\
\text { (OPT) }\end{array}$ & $\begin{array}{l}\text { Generation technology distribution will be optimized based on } \\
\text { minimum water consumption. }\end{array}$ \\
\hline $\begin{array}{c}\text { Dry cooling system } \\
\text { (DCS_BAU) }\end{array}$ & $\begin{array}{l}\text { The distribution of each generation technology will not change over } \\
\text { the period of the study and the cooling systems for all technologies, } \\
\text { except nuclear, will be assumed as dry cooling system starting in 2016. }\end{array}$ \\
\hline $\begin{array}{c}\text { DCS Optimization } \\
\text { (DCS_OPT) }\end{array}$ & $\begin{array}{l}\text { Optimization will be conducted based on dry cooling system for all } \\
\text { technologies, except nuclear, starting in 2016. }\end{array}$ \\
\hline
\end{tabular}

Below are the assumptions applied to the scenarios listed Table 1.

- All current power plants are assumed to operate between 2017 and 2035.

- The renewable energy potential is assumed to be used gradually during the study period.

- The share percentage of natural gas power plants is assumed to be between $30-40 \%$ over the years.

- The first unit of the nuclear power plants will start to operate in 2022, and the remaining units will gradually start operating until 2029.

\section{Results and discussions}

In the first phase of the study, the detailed power plant data is analyzed to determine the total water consumption based on cooling systems for each technology. As presented in Table 2, majority of natural gas and coal/lignite, all biogas, half of geothermal power plants use wet cooling towers which consume more water than once through or dry cooling systems.

Table 2. WCF and 2016 sharing percentages of the cooling systems based on installed capacities.

\begin{tabular}{|c|c|c|c|}
\hline $\begin{array}{c}\text { Technology/Fuel } \\
\text { Type }\end{array}$ & Wet Cooling Towers & Once Through System & Dry Cooling System \\
\hline Natural gas & $749 \mathrm{~m}^{3} / \mathrm{GWh}-48 \%$ & $378 \mathrm{~m}^{3} / \mathrm{GWh}-16 \%$ & $7.5 \mathrm{~m}^{3} / \mathrm{GWh}-37 \%$ \\
\hline Geothermal & $5299 \mathrm{~m}^{3} / \mathrm{GWh}-55 \%$ & Not Available $(\mathrm{NA})$ & $511 \mathrm{~m}^{3} / \mathrm{GWh}-45 \%$ \\
\hline Coal and lignite & $2600 \mathrm{~m}^{3} / \mathrm{GWh}-37 \%$ & $946 \mathrm{~m}^{3} / \mathrm{GWh}-53 \%$ & $106 \mathrm{~m}^{3} / \mathrm{GWh}-10 \%$ \\
\hline Biogas & $889 \mathrm{~m}^{3} / \mathrm{GWh}-100 \%$ & $\mathrm{Not}$ Available & $132 \mathrm{~m}^{3} / \mathrm{GWh}-\mathrm{NA}$ \\
\hline Nuclear & $2543 \mathrm{~m}^{3} / \mathrm{GWh}-\mathrm{NA}$ & $1018 \mathrm{~m}^{3} / \mathrm{GWh}-\mathrm{NA}$ & Not Available \\
\hline
\end{tabular}

By using the WCF determined from open literature for each cooling type used in each technology, total water consumption of each technology is calculated using Equation 1. The WCF for solar power plants is taken as $96 \mathrm{~m}^{3} / \mathrm{GWh}$. These values are then used to determine the water intensity (WI) of each technology. As it can be seen in Table 3, the maximum amount of water is consumed at the coal/lignite power plants in 2016, since it has high electricity generation sharing percentage in parallel with the relatively high WCF as given in Table 2. While the geothermal power plants have generation share less than $2 \%$, they resulted in high water consumption and the highest WI among all technology types. 
Table 3. Water consumption and water consumption intensity (WI) for 2016.

\begin{tabular}{|c|c|c|c|c|}
\hline Technology Type & $\begin{array}{c}\text { Generation } \\
(\mathbf{G W h})\end{array}$ & $\begin{array}{c}\text { Generation } \\
\text { Share, } \%\end{array}$ & $\begin{array}{c}\text { Water Consumption } \\
\left.\text { (Thousand } \mathbf{~ m}^{\mathbf{3}}\right)\end{array}$ & $\begin{array}{c}\text { Water Intensity } \\
(\mathbf{W I})\left(\mathbf{m}^{\mathbf{3}} \mathbf{/ G W h}\right)\end{array}$ \\
\hline Solar & 612 & $0.2 \%$ & 59 & 96 \\
\hline Wind & 15,370 & $5.7 \%$ & 0 & 0 \\
\hline Geothermal & 4,214 & $1.6 \%$ & 13,333 & 3,164 \\
\hline Biogas & 2,008 & $0.7 \%$ & 1,790 & 891 \\
\hline Hydropower & 67,067 & $24.8 \%$ & 0 & 0 \\
\hline Natural gas & 90,993 & $33.6 \%$ & 38,292 & 420 \\
\hline Coal/Lignite & 90,262 & $33.4 \%$ & 134,114 & 1,485 \\
\hline \hline Total & 270,526 & $100 \%$ & 187,588 & 693 \\
\hline
\end{tabular}

As presented LEAP program is used to determine the share distributions of the technologies between 2017 and 2035. For BAU and DCS scenarios, the shares of technologies in 2016 are assumed to be constant until 2022 as presents in

Fig. 1. After the nuclear power plants start to operate in Turkey in 2022, the remaining generation is then divided based on the shares of 2016 for both scenarios.

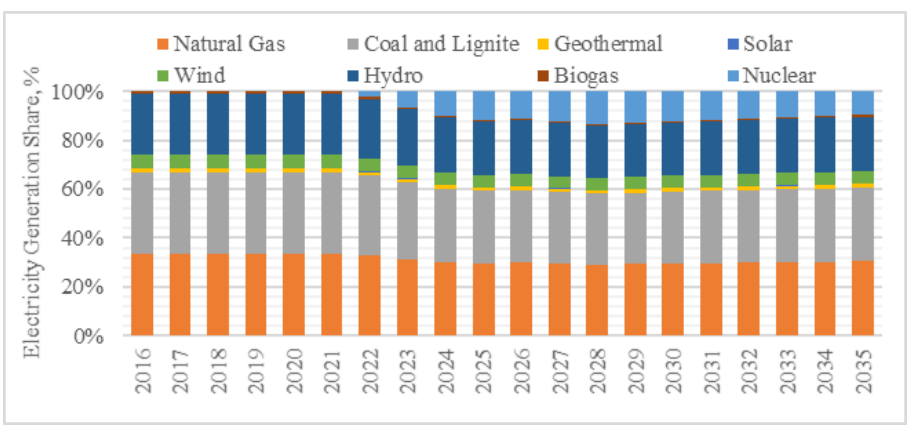

Fig. 1. Annual electricity generation shares for the BAU and DCS_BAU scenarios.

The shares of technology types for the OPT scenario determined based on the optimization of minimum water consumption at LEAP program is presented in Fig. 2. As it can be seen here, the shares of technologies with high WCF, such as geothermal and coal/lignite power plants, are replaced by the ones with lower WFC. Even though, the coal/lignite power plants have high WCF, their shares increase slightly after 2029 to supply the forecasted demand since other resources have reached their potential of dispatching.

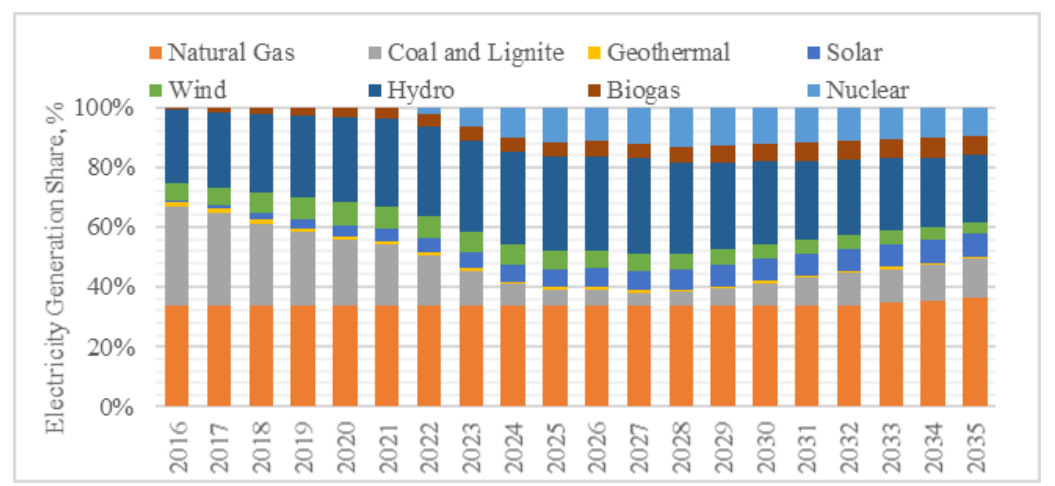

Fig. 2. Annual electricity generation shares for the OPT scenario. 
The last scenario applied to the LEAP model was the DCS_OPT which is based on optimizing the water consumption using dry cooling systems for all technologies. As can be seen in Fig. 3, unlike OPT scenario results, the shares of biogas and geothermal power plants decrease over the years due to their high WCF for dry cooling systems. Similar to the results of OPT scenario, the share of coal/lignite power plants start to increase after 2029.

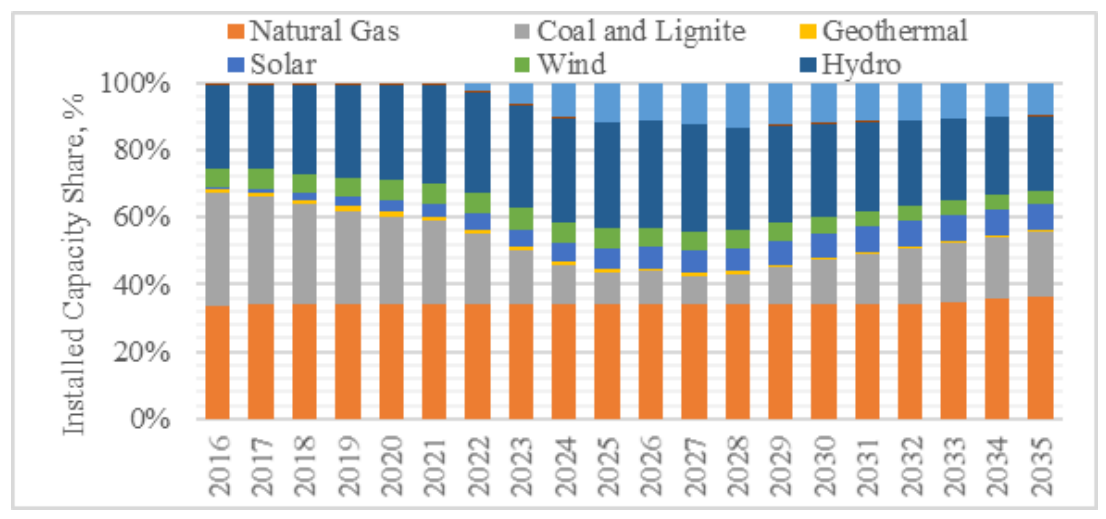

Fig. 3. Annual electricity generation share for the DCS_OPT scenario.

Using the estimated generation of each technology from LEAP model, the water consumption of each technology is calculated to determine the total water consumption between 2017 and 2035 as presented in Fig. 4.

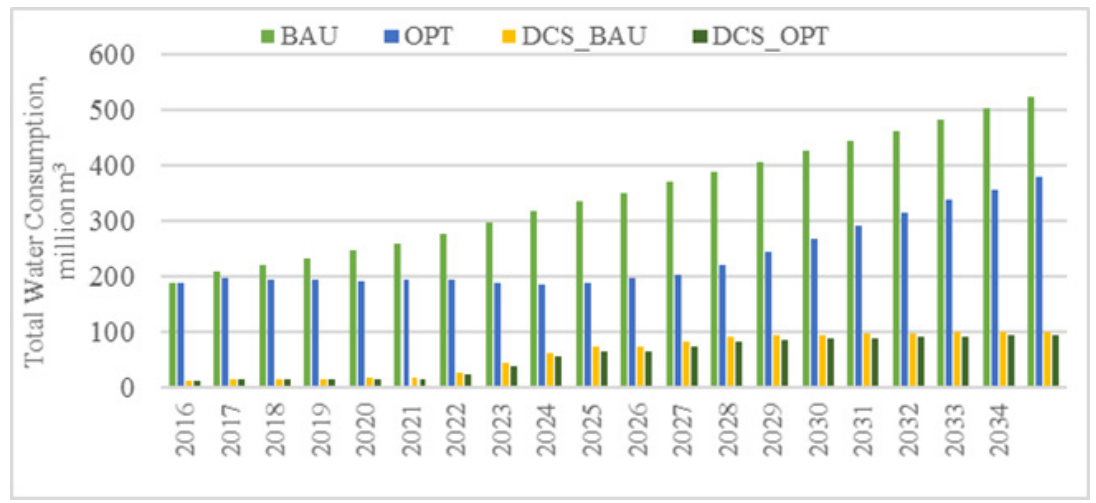

Fig. 4. Total water consumption over the study period based on four scenarios.

As it can be seen clearly from this figure, BAU scenario results in the highest water consumption in all years throughout the estimation period. As the electricity demand in 2035 is expected to be the double the amount in 2016, the total water demand is estimated to increase almost three folds by 2035 based on BAU scenario. Furthermore, the nuclear power plants will roughly increase the water consumption once they start to operate gradually between 2022 and 2028. Total water consumption reduces significantly when the technology shares are optimized based on WCF as done at OPT and DCS_OPT scenarios. The use of dry cooling systems for all technologies reduces the water consumption about $80 \%$. Even the dry cooling systems result in high decreases in the water consumption, they have lower heat transfer efficiencies compared to wet cooling systems, due to the heat capacity difference of water and air. In addition, these systems have higher capital costs than those of the wet ones. The annual WI determined based on each scenario is presented in Table 4. As it can be seen 
here, WI based on BAU scenario increases by $5 \%$ in 2035 , whereas WI based OPT scenario decreases by $25 \%$.

Table 4. Water intensity, WI, $\left(\mathrm{m}^{3} / \mathrm{GWh}\right)$ based on four scenarios.

\begin{tabular}{|c|c|c|c|c|c|}
\hline Scenario & $\mathbf{2 0 1 6}$ & $\mathbf{2 0 2 0}$ & $\mathbf{2 0 2 5}$ & $\mathbf{2 0 3 0}$ & $\mathbf{2 0 3 5}$ \\
\hline BAU & 693 & 693 & 731 & 732 & 726 \\
\hline OPT & 693 & 539 & 414 & 460 & 525 \\
\hline DCS_BAU & 47 & 47 & 159 & 163 & 141 \\
\hline DCS_OPT & 47 & 41 & 142 & 150 & 132 \\
\hline
\end{tabular}

In a similar project conducted in California, US, the annual WI was determined for the projected electricity generation [18]. The authors estimated that the WI would decrease from $1083 \mathrm{~m}^{3} / \mathrm{GWh}$ in 2010 to $965 \mathrm{~m}^{3} / \mathrm{GWh}$ in 2035 . In another study conducted in Texas, US, the WI for the electricity generation in 2010 was quantified as $1287 \mathrm{~m}^{3} / \mathrm{GWh}$ [19]. The WI determined in these studies are relatively higher the one estimated in this study. This is due to high share of nuclear power plants in the generation mixture and the high usage of wet cooling systems.

\section{Conclusion}

In this study, power plant data are gathered from various resources to determine the water consumption of all current power plants. The data analysis showed that the most common cooling system in Turkish power plants is the wet cooling system, which consumes the highest amount of water among all other cooling systems. Total water consumption in 2016 is determined as 187 million $\mathrm{m}^{3}$, and the WI for 2016 is calculated as $693 \mathrm{~m}^{3} / \mathrm{GWh}$. To optimize the technology mixture between 2017 and 2035 based on four scenarios, LEAP simulation program was used. The first scenario is BAU where 2016 technology shares are assumed to stay constant. Based on BAU technology mixture, the total water consumption is expected to increase by almost three folds parallel to the estimated increase in demand. The scenario in which water consumption is optimized (OPT) resulted in about $25 \%$ reduction in water consumption in 2035. In the third and fourth scenarios where it was assumed dry cooling systems are used for all thermoelectric power plants, expect nuclear, the water consumption and WI were reduced by almost $80 \%$. Even though, the dry cooling systems achieve high decrease in the water consumption, they have low efficiencies due to the heat capacity difference between water and air. Also, these systems have higher capital costs than those of the wet ones. So, the use of hybrid cooling systems can be recommended in which the system will use the wet component in the hot days and the dry component in the normal days to decrease the water consumption.

\section{References}

1. P. A. Torcellini, N. Long, J. Ron, Consumptive water use for US power production, NREL conference paper (2003)

2. B. Lamya, G. Boardman, J. Bigger, J. Energ. Eng.-ASCE 138, 246-257 (2012)

3. E. Mielke, L. D. Anadon, V. Narayanamurti, Water consumption of energy resource extraction, processing, and conversion, Belfer Center for Science and Int. Affairs (2010)

4. M. J. Rutberg, Modeling water use at thermoelectric power plants, $\mathrm{PhD}$ diss., Massachusetts Institute of Technology (2012) 
5. T. Havey, California's Coastal Power Plants: Alternative Cooling System Analysis, Golden Co., California (2008)

6. J. Macknick, R. Newmark, G. Heath, K. Hallet, A review of operational water consumption and withdrawal factors for electricity generating technologies, NREL, U.S. (2011)

7. L.L. Dale, N. Karali, D. Millstein, et al., Climatic Change 132, 223 (2015)

8. Comparison of Alternate Cooling Technologies for California Power Plants, EPRI, Palo Alto, CA, and California Energy Commission, Sacramento, CA (2002)

9. Turkey electricity energy production capacity projection of 5 years (2015-2019), [Online]. Available: www.teias.gov.tr [Accessed December 2016]

10. Enerji Atlasi, [Online]. Available: http://www.enerjiatlasi.com/. [Accessed December 2016]

11. Enka engineering for a better future, (2016). [Online]. Available: http://www.enka.com/ [Accessed 1 January 2017]

12. Green Power Through Innovation, (2016). [Online]. Available: http://exergy-orc.com [Accessed 1 January 2017]

13. A. Ashwood, D. Bharathan, Hybrid cooling systems for low-temperature geothermal power production, 1-62 (2011). Available at: http://digitalscholarship.unlv.edu

14. Energy demands on water resources: Report to Congress on the interdependency of energy and water, U.S. Department of Energy, U.S. (2006)

15. T. J. Feeley, T. J. Skone, G. J. Stiegel, A. McNemar, M. Nemeth, B. Schimmoller, J. T. Murphy, L. Manfredo, Energy 33, 1, (2008)

16. User guide for version LEAP, (2015). [Online]. Available: www.energycommunity.org [Accessed 20 December 2016]

17. Blue Book (Mavi kitap), MENR, (2015), Available: www.enerji.gov.tr [Accessed 20 December 2016]

18. H. Cooley, J. Fulton, P. H. Gleick, N. Ross, P. Luu, Water for energy, Report from Pacific Institute, USA (2011)

19. B. Scanlon, R. C. Reed, I. Duncan, W. F. Mullican, M. Young, Int. J. Environ. Sci. Technol. 47, 19 (2013) 